\title{
Insulin-like growth factor 1 inhibits phagocytosis of alveolar epithelial cells in asthmatic mice
}

\author{
MIMI MU ${ }^{1 *}$, FENGJIAO WU $^{1 *}$, JING HE$^{1 *}, \mathrm{XU}_{\text {TANG }}^{2}$, HUA MA $^{1}$, SHUJUN GUO $^{1}$ and CHUANWANG SONG ${ }^{1}$ \\ ${ }^{1}$ Department of Immunology, Anhui Provincial Key Laboratory of Infection and Immunity; \\ ${ }^{2}$ Department of Clinical Laboratory Medicine, Bengbu Medical College, Bengbu, Anhui 233030, P.R. China
}

Received December 24, 2018; Accepted June 4, 2019

DOI: $10.3892 / \mathrm{mmr} .2019 .10456$

\begin{abstract}
The phagocytosis of apoptotic cells by alveolar epithelial cells helps to eliminate airway inflammation. Insulin-like growth factor 1 (IGF-1) regulates cell metabolism and proliferation, and promotes cell survival, while it may also promote the proliferation and differentiation of alveolar epithelial cells during the repair of lung injury. The present study investigated the effect of IGF-1 on the phagocytic activity of alveolar epithelial cells, a nonprofessional phagocyte. IGF-1 was elevated in lung tissue and bronchoalveolar lavage fluid obtained from mice with ovalbumin-induced asthma. IGF-1 was reduced by $50 \%$ in the lung tissue and by nearly $100 \%$ in the bronchoalveolar lavage fluid in asthmatic mice established by depletion of alveolar macrophages using 2-chloroadenosine. In addition, interleukin-33 induced IGF-1 production in primary alveolar macrophages. It was also observed that IGF-1 inhibited the phagocytosis of fluorescent microspheres and apoptotic cells by MLE-12 alveolar epithelial cells. Antibody blocking of IGF-1 enhanced the phagocytosis of fluorescent microspheres and apoptotic cells, and significantly reduced inflammatory cell infiltration in airway and perivascular tissues. The elevated IGF-1 level in the lungs of asthma model mice was mainly produced in alveolar macrophages. Taken together, the current study demonstrated that IGF-1 inhibited phagocytosis by alveolar epithelial cells, and that IGF-1 blockade enhanced the phagocytic activity and alleviated airway inflammation. These results support the potential use of IGF-1 as a target in the treatment of asthma.
\end{abstract}

Correspondence to: Dr Chuanwang Song, Department of Immunology, Anhui Provincial Key Laboratory of Infection and Immunity, Bengbu Medical College, 2600 Songhai Avenue, Bengbu, Anhui 233030, P.R. China

E-mail: chuanwangsong@163.com

*Contributed equally

Key words: insulin-like growth factor 1, phagocytosis, alveolar epithelial cell, asthma

\section{Introduction}

Phagocytosis, first described by Metchnikoff $>100$ years ago, is the engulfing and internalizing of particles with a size of $\geq 0.5 \mu \mathrm{m}$ by cells. Unlike micropinocytosis, phagocytosis is initiated by the recognition and binding of cell surface receptors to target particles $(1,2)$. Professional phagocytes, including macrophages, neutrophils and dendritic cells, participate in the first line of defense against infection by clearing pathogens from the sites of infection (3). Nonprofessional phagocytes, such as epithelial and endothelial cells, and fibroblasts, do not internalize pathogens, but clear senescent cells by engulfing apoptotic bodies $(4,5)$. Therefore, nonprofessional phagocytes avoid the release of inflammatory contents of apoptotic cells in this way, and thus serve an important role in maintaining tissue homeostasis. Recently, Juncadella et al (6) reported that the function of airway epithelial cells to phagocytose apoptotic cells was attenuated in asthmatic mice, thereby forming interleukin (IL)-33-dependent allergic airway inflammation. This indicates that the engulfment of apoptotic cells by airway epithelial cells is an important mechanism for the regression of airway inflammation.

Insulin-like growth factor 1 (IGF-1) is a small $7.6-\mathrm{kDa}$ peptide that exhibits 50\% homology with insulin. It is a hormone with local activity following autocrine or paracrine secretion, and regulates cell survival, metabolism, proliferation and differentiation $(7,8)$. IGF-1 is predominantly produced in the liver, while it is also produced in certain other organs, such as the lungs, where it is elevated under conditions of acute lung injury, pulmonary fibrosis and asthma (9). IGF-1 promotes the proliferation and differentiation of alveolar epithelial cells during the repair of hypoxia-induced lung injury (10). Although IGF-1 has been demonstrated to promote the phagocytic activity of mouse macrophages (11), its effects on nonprofessional phagocytes, such as alveolar epithelial cells, have not been described to date. Recently, it has been reported that the concentration of IGF-1 was elevated in the lung tissues of asthmatic mice (12).

As the engulfment of apoptotic cells by the airway epithelium affects the progression of airway inflammation in asthmatic mice, the effect of IGF-1 on the phagocytic function of alveolar epithelial cells was investigated in the present study. The study revealed that IGF-1 inhibited the phagocytosis of fluorescent microspheres and apoptotic cells by MLE-12 
alveolar epithelial cells and by mouse alveolar epithelial cells from primary cultures. IGF-1 was elevated in the lung tissue and bronchoalveolar lavage fluid (BALF) of asthmatic mice, whereas IGF-1 blockade promoted phagocytosis by alveolar epithelial cells and reduced airway inflammation.

\section{Materials and methods}

Cell culture. Primary alveolar epithelial cells and MLE-12 alveolar epithelial cells (Shanghai Jining Shine Biotechnology Corporation) were cultured in Dulbecco's modified Eagle's medium with 10\% FBS (HyClone; GE Healthcare Life Sciences) containing $1 \%$ penicillin and streptomycin (Beyotime Institute of Biotechnology) in a $5 \% \mathrm{CO}_{2}$ incubator at $37^{\circ} \mathrm{C}$. When the cultures reached $80-90 \%$ confluency, the cells were harvested with $0.25 \%$ pancreatin for subculturing MLE-12 cells. The cells were passaged every 1-2 days.

Animal model and treatment protocol. A total of 30 female $\mathrm{BALB} / \mathrm{c}$ mice were purchased from the Experimental Animal Center of Bengbu Medical College. The mice (4-weeks-old) were housed in pathogen-free grade conditions with 60-70\% humidity under a $12 \mathrm{~h} \mathrm{light} / \mathrm{dark}$ cycle at $25^{\circ} \mathrm{C}$ with free to access food and water. The process for establishing an asthma model is illustrated in Fig. 1. Briefly, mice weighing $15-30 \mathrm{~g}$ were intraperitoneally injected with $200 \mu \mathrm{l}$ of a sensitizing solution containing $50 \mathrm{mg}$ ovalbumin (Sigma-Aldrich; Merck KGaA) and $2 \mathrm{mg}$ aluminum hydroxide (Thermo Fisher Scientific, Inc.) on days 0,7 and 14 . Beginning on day 21, the mice were placed in an inhalation chamber and treated with aerosolized $5 \%$ ovalbumin for 30 min once a day for 1 week. Control mice received a mock challenge with phosphate-buffered saline (PBS). To deplete alveolar macrophages, asthma model mice received 2-chloroadenosine (2-CA; Sigma-Aldrich; Merck $\mathrm{KGaA}$ ) administered in four doses of $1 \mu \mathrm{g} / 20 \mu \mathrm{l}$ once every 3 days, beginning on day 20 . For IGF-1 blockade, asthma model mice were administered anti-IGF-1 antibody (1:10; cat. no. ab9572; Abcam) by intranasal drip in a dose of $1 \mu \mathrm{g} / 20 \mu 1$ once every 3 days, beginning on day 20 . Animal experiments in the present study were approved by the Ethics Committee of the Bengbu Medical College (Bengbu, China).

Collection of BALF and alveolar macrophages. Mice were anesthetized with $1 \%$ chloral hydrate prior to tracheal intubation, and bronchoalveolar lavage with $0.6 \mathrm{ml}$ PBS was performed for six consecutive times. The BALF samples obtained from each lavage were centrifuged at $233 \mathrm{x}$ g for $5 \mathrm{~min}$ at $4^{\circ} \mathrm{C}$. The supernatant was collected for cytokine assays. Next, the red blood cells were lysed, and the pellet was resuspended in RPMI-1640 medium (HyClone; GE Healthcare Life Sciences) and then seeded onto 6-well plates at a final density of $5 \times 10^{5}$ cells/well. The cells were allowed to adhere for at least $2 \mathrm{~h}$ before washing away the nonadherent cells to expose the adherent alveolar macrophages. The purity of the isolated macrophages was $>95 \%$.

Isolation of primary alveolar epithelial cells. Mice were anesthetized with chloral hydrate prior to tracheal intubation and injection of $10-15 \mathrm{ml}$ of air directly to the lungs. The pulmonary artery was lavaged with PBS, and bronchoalveolar

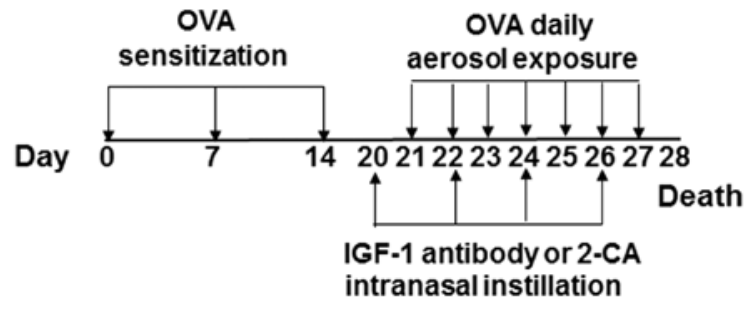

Figure 1. Flow chart of the study procedures. BALB/c mice were sensitized by intraperitoneal injection of OVA bound to aluminum hydroxide and challenged with aerosolized 5\% OVA. 2-CA or IGF-1 blocking antibody was administered by intranasal instillation. OVA, ovalbumin; 2-CA, 2-chloroadenosine; IGF-1, insulin-like growth factor 1.

lavage was performed through the trachea until the lavage fluid was clear and transparent. Intrapulmonary digestion was performed by two successive injections of $15 \mathrm{ml} 0.5 \%$ trypsin into the lungs for $10 \mathrm{~min}$ each. Digestion was stopped with RPMI-1640 medium containing 20\% fetal calf serum (FCS). The trachea and bronchi were removed, following which the lung tissue was dissected and placed in RPMI-1640 medium. The lung tissue was cut into sections of $<1 \mathrm{~mm}^{3}$ in size, ground between frosted glass sheets, and passed through 200 mesh and 400 mesh screens to obtain a suspension of primary alveolar epithelial cells.

Induction and assay of apoptotic cells. MLE-12 and primary alveolar epithelial cells $\left(4 \times 10^{5}\right.$ cells/well) were stimulated with $0.25 \mu \mathrm{M}$ curcumin (Sigma-Aldrich; Merck KGaA) for $72 \mathrm{~h}$. Subsequently, the cells were stained for $20 \mathrm{~min}$ with Annexin V-fluorescein isothiocyanate (FITC) and propidium iodide using an assay kit (Beyotime Institute of Biotechnology), following the manufacturer's protocol. Apoptosis was assayed by flow cytometry (FACSCalibur; BD Biosciences, Franklin Lakes, NJ, USA) within $1 \mathrm{~h}$ of staining.

Phagocytosis assay. MLE-12 and freshly isolated alveolar epithelial cells $\left(5 \times 10^{4}\right.$ cells/well) were stimulated for $48 \mathrm{~h}$ with 100, 200, 300, 500 and 1,000 ng/ml IGF-1 (Abcam). The cells were then incubated with $1 \mu \mathrm{l}$ of a suspension of $4.55 \times 10^{7}$ fluorescent microspheres ( $1 \mu \mathrm{m}$ in diameter) for $2 \mathrm{~h}$ before washing twice in PBS with 5\% FCS and fixing in 4\% paraformaldehyde (PFA). Cells that had induced phagocytosis of fluorescent microspheres were detected with a FACSCalibur flow cytometer.

Furthermore, to assay the phagocytosis of apoptotic cells, activated MLE-12 or primary alveolar epithelial cells $\left(5 \times 10^{4}\right.$ cells/well) were seeded into 6-well plates, and cocultured for $4 \mathrm{~h}$ with FITC-stained apoptotic MLE-12 cells. The cells were then washed twice with PBS containing 5\% FCS and fixed with $4 \%$ PFA. The phagocytosis of FITC-labeled apoptotic cells was detected by flow cytometry.

Western blot assay. Isolated mouse lung tissue was washed with PBS, and protein extracts were prepared with NP-40 cell lysis buffer (Beyotime Institute of Biotechnology). The protein concentration of the cell lysates was measured using a bicinchoninic acid protein assay kit (Beyotime Institute of Biotechnology). Following separation by $12 \%$ sodium dodecyl sulfate-polyacrylamide gel electrophoresis, the protein 
A

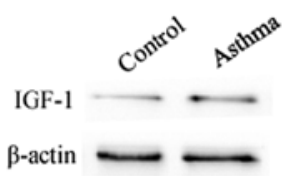

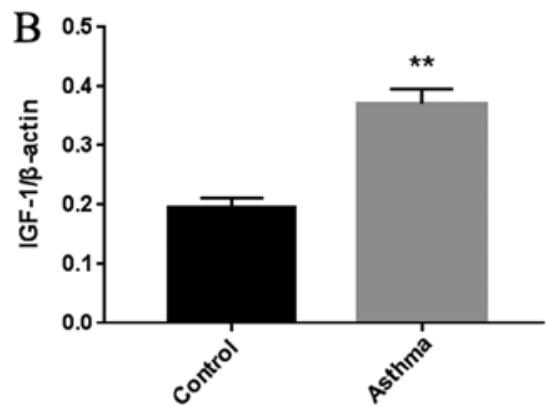



Figure 2. Increased IGF-1 protein in the lungs of asthmatic mice. (A) Representative western blot and (B) quantified levels of IGF-1 expression in lung tissues obtained from normal control and asthmatic mice. Densitometric analysis was conducted, and the expression of IGF-1 is shown relative to that of $\beta$-actin (C) ELISA of IGF-1 level in the bronchoalveolar lavage fluid of normal control and asthmatic mice. Data are expressed as the mean \pm standard deviation of three independent experiments. ${ }^{* *} \mathrm{P}<0.01$ vs. control group. IGF-1, insulin-like growth factor 1.

samples were transferred to polyvinylidene difluoride (PVDF) membranes. Next, the PVDF membranes were blocked in Tris-buffered saline and Tween 20 (TBST) with 5\% skim milk powder at $25^{\circ} \mathrm{C}$ for $2 \mathrm{~h}$. The membranes were washed with TBST solution and incubated overnight at $4^{\circ} \mathrm{C}$ with IGF-1 (1:1,000; cat. no. ab9572; Abcam) and $\beta$-actin (1:1,000; cat. no. AF0003; Beyotime Institute of Biotechnology) primary antibodies. Membranes were washed and then incubated with horseradish peroxidase-conjugated goat anti-mouse secondary antibody (1:1,000; cat. no. A0208; Beyotime Institute of Biotechnology) at $25^{\circ} \mathrm{C}$ for $2 \mathrm{~h}$. Subsequently, the protein bands were read by enhanced chemiluminescence using a BeyoECL Plus kit, and strip density analysis was performed with ImageJ software 6.0 (https://imagej.nih.gov/ij/).

Enzyme-linked immunosorbent assay (ELISA). The content of IGF-1 and IL-33 in the BALF supernatants, as well as IGF-1 in lung tissues were assayed using commercially available ELISA kits (cat. nos. K02016571 and M27131086; Cusabio Biotech Co., Ltd.), following the manufacturer's protocol.

Lung histology. The mouse lungs were surgically obtained from mice $24 \mathrm{~h}$ after final antigen or mock challenge. Lung tissue was fixed at $25^{\circ} \mathrm{C}$ for 1 week in $4 \%$ PFA, dehydrated in a graded alcohol series, embedded in paraffin and sectioned at $5 \mu \mathrm{m}$. Following dewaxing and rehydration, the sections were stained with hematoxylin-eosin, and observed and photographed under a light microscope.

Statistical analysis. The results are expressed as the mean \pm standard deviation. Similar results were obtained from three independent experiments. Statistical analysis was performed with SPSS software, version 16.0 (SSPS, Inc., Chicago, IL, USA). One-way analysis of variance was conducted to evaluate multiple group comparisons, while Student's t-tests were used to evaluate comparisons between two groups. P-values of $<0.05$ were considered to denote statistically significant differences.

\section{Results}

Increased IGF-1 protein expression in the lungs of asthmatic mice. As shown in Fig. 2A, IGF-1 protein expression was significantly higher in the lung tissue of asthmatic mice as compared with that in normal control mice. IGF-1 protein expression was also markedly higher in the BALF of asthmatic mice compared with that in normal mice (Fig. 2B).

Elevated IGF-1 expression in the lungs of asthmatic mice primarily results from synthesis in alveolar macrophages. IL-33, a cytokine that promotes airway inflammation, is elevated in the serum of asthma patients, and is associated with disease severity (13). In the current study, IL-33 was significantly elevated in the BALF of asthma model mice (Fig. 3A). IGF-1 expression was also significantly increased in primary alveolar macrophages stimulated by IL-33 in vitro (Fig. 3B). Following the depletion of alveolar macrophages by 2-CA, the elevation of IGF-1 expression in the lung tissues of asthmatic mice decreased by $50 \%$, while the elevation of IGF-1 in the BALF almost completely disappeared (Fig. 3C and D). The results of Fig. 3C and D indicated that the increase in IGF-1 in the lung tissues of asthma model mice primarily resulted from synthesis in alveolar macrophages.

IGF-1 inhibits the phagocytic activity of alveolar epithelial cells. The phagocytosis of apoptotic cells by alveolar epithelial cells has been demonstrated to reduce airway inflammation, and IGF-1 significantly inhibited the phagocytosis of MLE-12 and primary alveolar epithelial cells. The results of the treatment of MLE-12 cells with 100-1,000 ng/ml IGF-1 on the phagocytosis of fluorescent microspheres are displayed in Fig. 4A and B. After $12 \mathrm{~h}$ of treatment, the phagocytic activity of MLE-12 cells significantly decreased at doses of 200, 300 and $500 \mathrm{ng} / \mathrm{ml}$, with the inhibitory effect reaching a peak at $300 \mathrm{ng} / \mathrm{ml} \mathrm{IGF-1.} \mathrm{Following} \mathrm{stimulation} \mathrm{of} \mathrm{MLE-12}$ cells with $100 \mathrm{ng} / \mathrm{ml}$ curcumin for $24 \mathrm{~h}$, the percentage of cells in late apoptosis was $97.8 \%$ compared with that of $2.95 \%$ for unstimulated MLE-12 cells (Fig. 4C). Upon treatment with $300 \mathrm{ng} / \mathrm{ml} \mathrm{IGF-1} \mathrm{for} 4 \mathrm{~h}$, the phagocytosis decreased to $32.6 \%$ (Fig. 4D and E). However, when treatment with $300 \mathrm{ng} / \mathrm{ml}$ IGF-1 was performed for $12 \mathrm{~h}$, it resulted in a significant reduction in the phagocytosis of fluorescent microspheres and apoptotic cells by primary alveolar epithelial cells (Fig. 4F-I).

Antibody blocking of IGF-1 antibody promotes the phagocytic activity of primary alveolar epithelial cells and reduces lung inflammation in asthma model mice. Anti-IGF-1 blocking antibody was administered by nasal drops during the 



Figure 3. Increase in IGF-1 expression in the lung tissues of asthmatic mice primarily resulted from synthesis in alveolar macrophages. (A) ELISA of IL-33 expression in the BALF of normal control and asthmatic mice. (B) Primary alveolar macrophages from normal control mice were seeded into 6-well plates and stimulated with IL-33 (100 ng/ml) for $48 \mathrm{~h}$; next, IGF-1 expression in the supernatant was determined by ELISA. The asthmatic mice were treated by intranasal instillation of 2-CA, and IGF-1 expression in (C) lung tissues and (D) BALF of asthmatic mice were examined by western blot and ELISA. Data are expressed as the mean \pm standard deviation of three independent experiments. ${ }^{*} \mathrm{P}<0.05$ and ${ }^{* * *} \mathrm{P}<0.01$ vs. control group; ${ }^{\# \#} \mathrm{P}<0.01$ vs. asthma model mice. IGF-1, insulin-like growth factor 1; IL-33, interleukin-33; BALF, bronchoalveolar lavage fluid.

development of the asthma model. Subsequently, primary alveolar epithelial cells were isolated from mouse lung tissue, and their phagocytic activity was assayed with fluorescent microspheres and apoptotic cells. Blocking IGF-1 in the asthma model mice significantly enhanced the phagocytosis of fluorescent microspheres and apoptotic cells by primary alveolar epithelial cells (Fig. 5A and B). Compared with the normal mice, the asthmatic mice exhibited extensive lung inflammation with distinct perivascular and peribronchial cuffing. Intranasal instillation of IGF-1 blocking antibody significantly decreased the infiltration of inflammatory cells around the airways and blood vessels, and decreased the thickness of the bronchial mucosa and airway secretions (Fig. 5C). Hence, IGF-1 blockade also significantly reduced lung airway inflammation in asthma model mice.

\section{Discussion}

In the mouse model established in the present study, IGF-1 levels were found to be significantly elevated in the lung tissues and BALF of asthmatic mice compared with the normal controls. IGF-1 is a peptide of approximately 70 amino acids containing four domains; it mediates cell growth, metabolism, proliferation and differentiation following binding to the IGF-1 receptor (IGF-1R) $(8,14)$. It is active in lung development and various disease states, such as inflammation, fibrosis and tumors (9). Numerous studies have reported increased IGF-1 mRNA expression in intrabronchial biopsy tissue obtained from asthmatic patients and patients with tracheal epithelial fibrosis (15). In addition, Yao et al (12) reported increased IGF-1 protein expression, assayed by immunohistochemistry, in lung tissues from asthma model mice. The results of the present study are consistent with previous reports, all of which support further study of IGF-1 as a therapeutic target in asthma.

IL-33 was found to be elevated in the BALF of asthma model mice in the current study (Fig. 3A). It is known that IL-33 promotes systemic T helper 2 (Th2) cell responses and is constitutively expressed in a variety of tissues, including the airways of asthmatic patients, particularly those with severe disease $(16,17)$. IL-33 activity is mediated by binding to its ST2 receptor, which is present on macrophages (18). IL-33 binding to alveolar macrophages can increase the expression of the mannose receptor IL-4Ra, as well as the production of C-C motif chemokine ligand 24 (CCL24) and CCL17, thus contributing to allergic inflammation $(19,20)$. In the asthma 

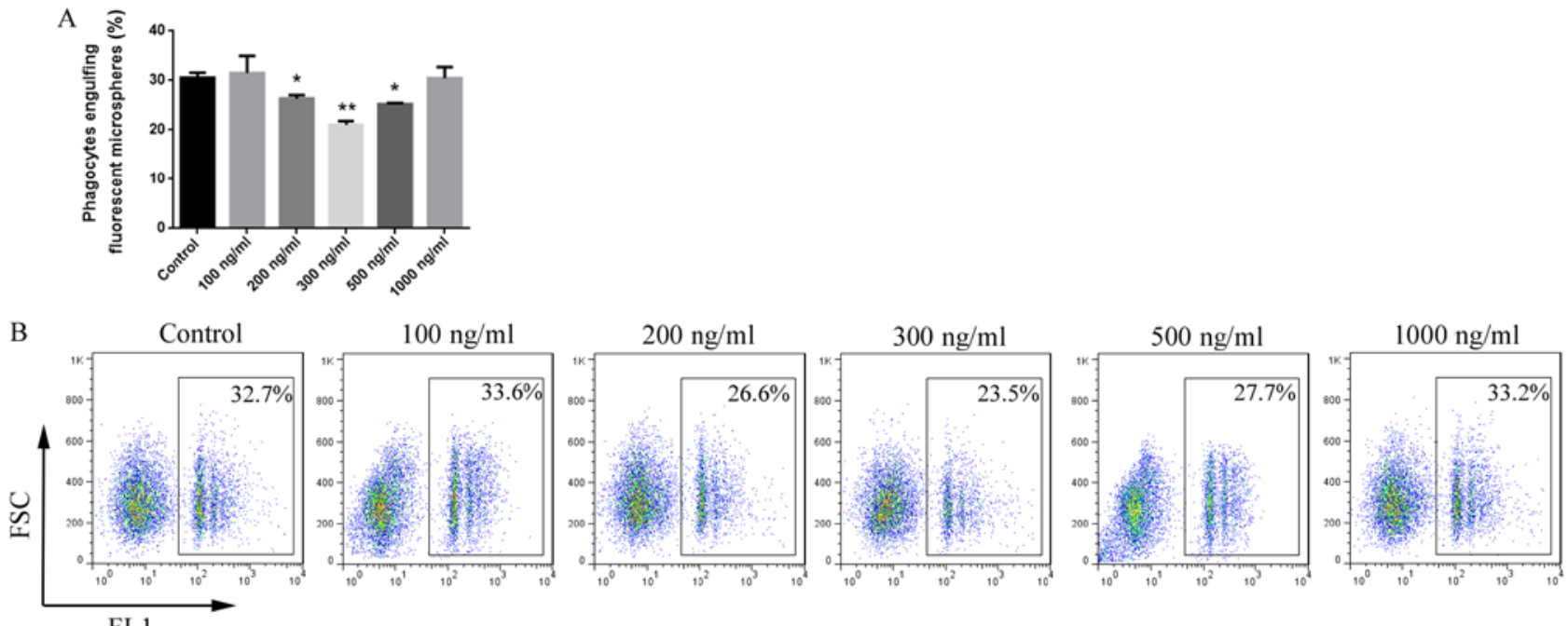

FL1


D

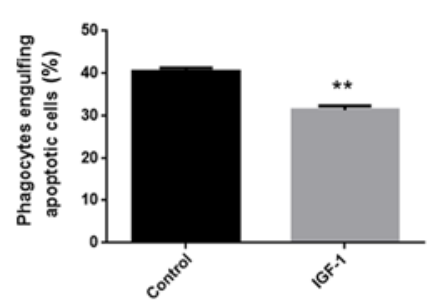

E
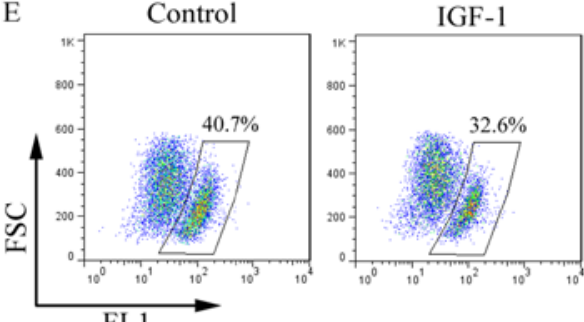

F

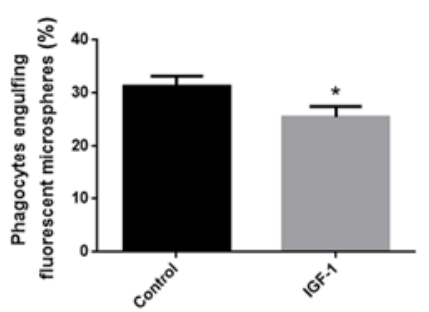

H

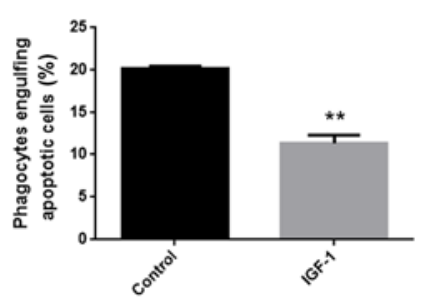

G
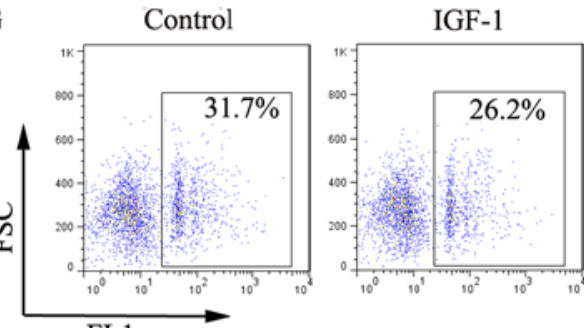

FL1

I

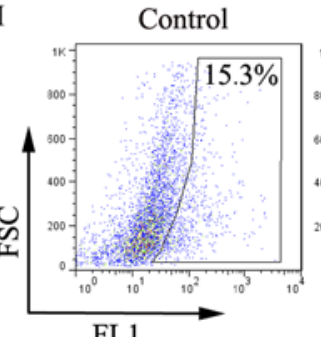

IGF-1

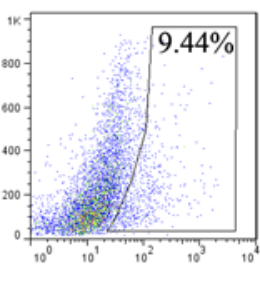

Figure 4. IGF-1 inhibits phagocytosis of MLE-12 and primary alveolar epithelial cells. (A) Percentage of phagocytosis of fluorescent microspheres, and

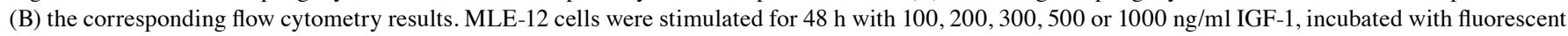
microspheres $\left(4.55 \times 10^{7}\right.$ particles) for $12 \mathrm{~h}$ and then examined by flow cytometry to assess the phagocytosis. (C) MLE-12 cells were stimulated with curcumin for $72 \mathrm{~h}$, stained with Annexin V-FITC and propidium iodide, and then apoptosis was assayed by flow cytometry. (D) Phagocytosis of apoptotic cells, and (E) the corresponding flow cytometry results of MLE-12 cells stimulated for $6 \mathrm{~h}$ with $300 \mathrm{ng} / \mathrm{ml}$ IGF-1. Following treatment, the cells were cocultured with FITC-stained apoptotic MLE-12 cells for $4 \mathrm{~h}$, and then apoptosis was assayed by flow cytometry. (F) Phagocytosis of fluorescent microspheres and (G) corresponding flow cytometry results, as well as the $(\mathrm{H})$ phagocytosis of apoptotic cells and (I) corresponding flow cytometry results, of primary alveolar epithelial cells treated with $300 \mathrm{ng} / \mathrm{ml}$ IGF-1 for $12 \mathrm{~h}$. Following treatment, the cells were cocultured with fluorescent microspheres or apoptotic MLE-12 cells for $4 \mathrm{~h}$, and then assessed by flow cytometry. Data are expressed as the mean \pm standard deviation of three independent experiments. ${ }^{*} \mathrm{P}<0.05$ and ${ }^{* *} \mathrm{P}<0.01 \mathrm{vs}$. unstimulated control group. IGF-1, insulin-like growth factor 1.

model mice investigated in the present study (Fig. 3B), IL-33 promoted IGF-1 expression by alveolar macrophages. IGF-1 production has been reported in endothelial cells, epithelial cells, fibroblasts and macrophages, among others $(21,22)$. In addition, Wang et al (23) reported that epidermal T cells can produce IGF-1. In the present study, the increase in IGF-1 

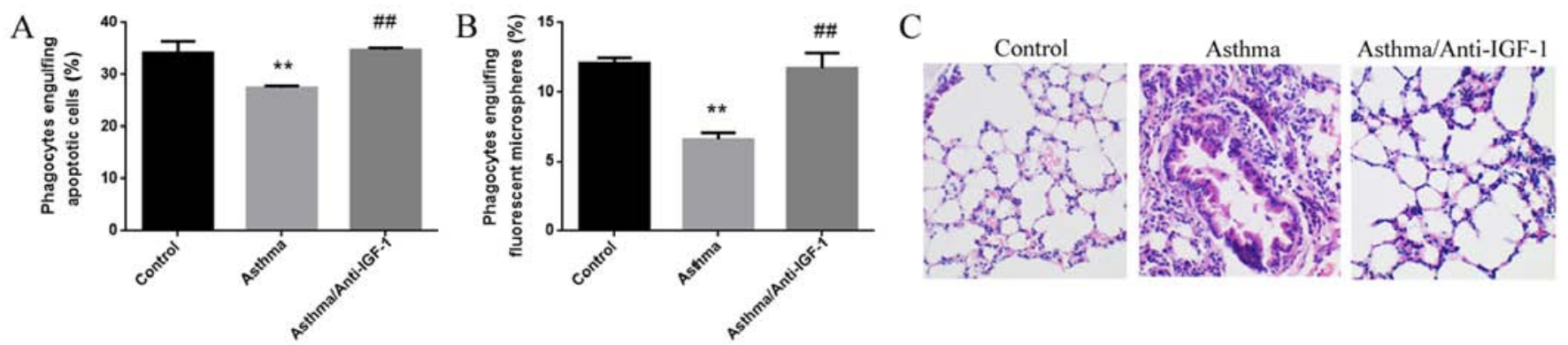

Figure 5. Antibody blocking of IGF-1 enhanced the phagocytic activity of alveolar epithelial cells and reduced airway inflammation in asthma model mice. Subsequent to intranasal instillation of anti-IGF-1 blocking antibody, primary alveolar epithelial cells were isolated and seeded into 6-well plates. Fluorescent microspheres or FITC-stained apoptotic MLE-12 cells were added, and the phagocytosis of (A) fluorescent microspheres or (B) apoptotic cells was assayed by flow cytometry. (C) Representative images of hematoxylin-eosin staining of lung tissue from mice in the treatment groups (magnification, x200). A representative image from three experiments is displayed. ${ }^{* *} \mathrm{P}<0.01$ vs. normal controls; ${ }^{\# \#} \mathrm{P}<0.01$ vs. asthma model mice. IGF-1, insulin-like growth factor 1.

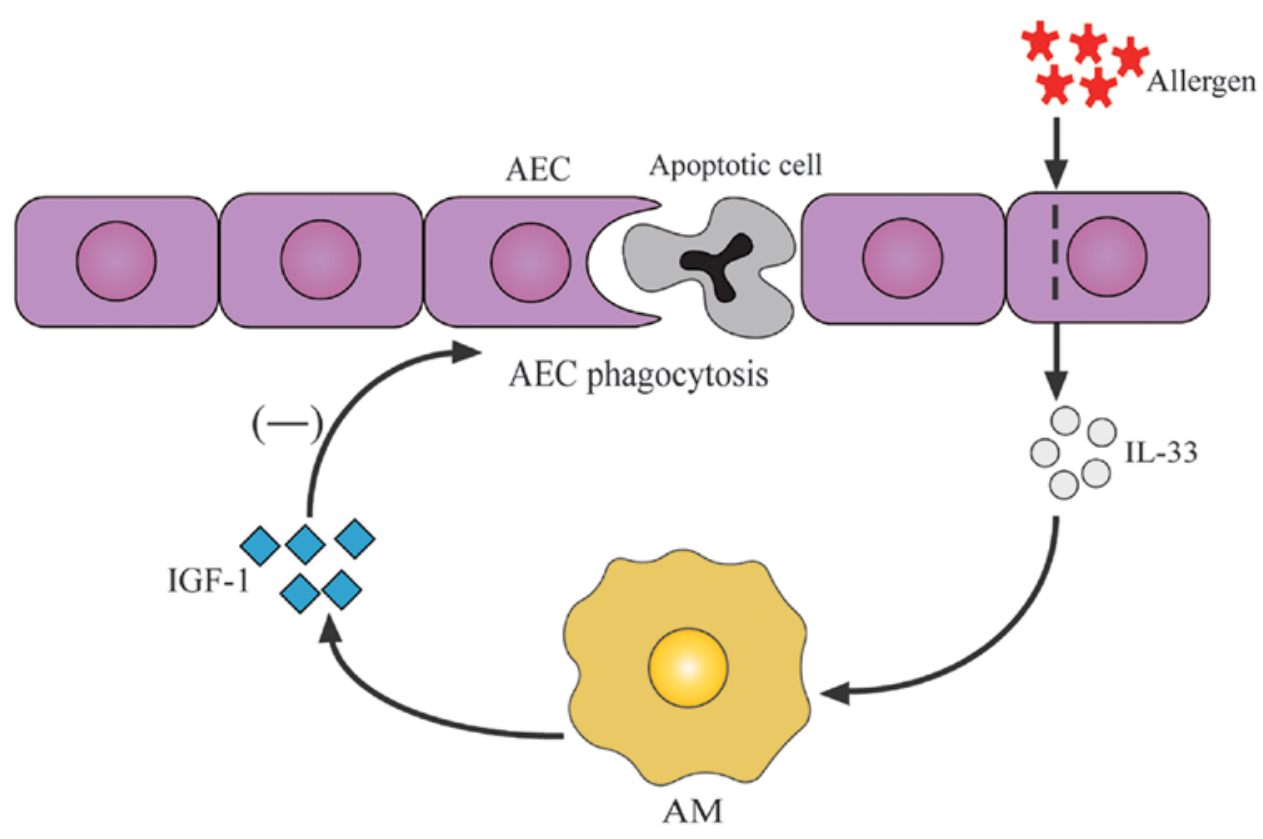

Figure 6. Schematic illustrating how AM-derived IGF-1 is thought to promote the phagocytosis of apoptotic cells in the airway of asthmatic mice. Allergen stimulation increases IL-33 secretion in the airways of asthmatic mice, which in turn induces IGF-1 production by AM. IGF-1 then inhibits phagocytosis of apoptotic cells by the surrounding AEC. IGF-1, insulin-like growth factor 1; AM, alveolar macrophages; AEC, alveolar epithelial cells.

that was detected in the asthma model animals was mainly produced in alveolar macrophages. This result is in line with the findings of Fritz et al (24), who demonstrated that alveolar macrophage-derived IGF-1 induced the proliferation of lung epithelial cells.

In the asthma model established in the current study, epithelial cells were nonprofessional phagocytes that helped to maintain tissue homeostasis by clearing apoptotic bodies. Allergens can stimulate the apoptosis of airway epithelial cells, whereas the surrounding intact epithelial cells can phagocytose the apoptotic cells and secrete anti-inflammatory cytokines. Airway epithelial cells, thus, regulate inflammation by phagocytosis (6). In the established model, IGF-1 prevented the phagocytosis of apoptotic cells by alveolar epithelial cells, thus increasing the release of inflammatory contents from apoptotic cells, thereby aggravating airway inflammation. Therefore, blocking IGF-1 improved airway inflammation and lung histopathology in asthmatic mice. IGF-1R-deficient mice are less susceptible to skin inflammation in comparison with normal mice, indicating that IGF-1 signaling promotes inflammation (25). A previous study has reported reduced airway hyperresponsiveness, mucus secretion and eosinophil infiltration of airway tissues in IGF-1R-deficient asthmatic mice (26). These observations are consistent with the involvement of IGF-1 in the development of asthma.

Aerobic training is recommended as an adjuvant therapy for asthma patients, since it reduces the expression of proinflammatory signals, including IGF-1 and peribronchial leukocyte activation, leading to reduced airway inflammation and Th2 responses $(27,28)$. The results of the mouse model described in the current study add to the evidence obtained from other asthma models that IGF-1 is a proinflammatory signal. Such evidence suggested that creatine supplementation promotes goblet cell proliferation, and upregulates the expression levels of IL-5, inducible nitric oxide synthase and proinflammatory mediators, such as IGF-1, in epithelial cells $(29,30)$. 
To date, few studies have investigated the association of IGF-1 signaling with phagocytosis. A study by Xiao et al (31) did not identify an effect of IGF-1 on the phagocytosis of peritoneal macrophages. Furthermore, Dos Santos Reis et al (11) reported that IGF-1 promoted phagocytosis by J774 macrophage cells. By contrast, in the current study model, IGF-1 inhibited phagocytosis by MLE-12 alveolar epithelial cells and primary alveolar epithelial cells. The differences in the findings of these studies may be the result of using different target cells.

In conclusion, the effects of IGF-1 on the phagocytosis of alveolar epithelial cells may represent a novel regulatory mechanism of airway inflammation, which is illustrated in Fig. 6. The results suggested that IL-33 was elevated in the airway of asthmatic mice and induced IGF-1 production by alveolar macrophages. IGF-1 then prevented the phagocytosis of apoptotic cells by alveolar epithelial cells and increased the release of inflammatory contents of apoptotic cells, thus leading to increased airway inflammation. Recurrent airway inflammation leads to airway hyperresponsiveness and airway remodeling, which exacerbates asthma. Nevertheless, in order to further explain the role of IGF-1 in the pathogenesis of asthma, it is necessary to construct an asthma model using IGF-1-deficient mice, and then observe airway inflammation and airway remodeling, which will be the focus of our future work. These efforts will support IGF-1 as a potential therapeutic target for the treatment of asthma.

\section{Acknowledgements}

Not applicable.

\section{Funding}

The present study was supported by grants from the National Science Foundation of China (grant nos. 81273273 and 81801573), and the Anhui Provincial Natural Science Foundation (grant nos. 1708085MH218 and 1808085QH253).

\section{Availability of data and materials}

The datasets used and/or analyzed during the current study are available from the corresponding author on reasonable request.

\section{Authors' contributions}

MM, FW, JH and XT performed the experiments. HM, SG and CS conducted data interpretation and analysis. CS wrote the manuscript. All authors have read and approved the final manuscript.

\section{Ethics approval and consent to participate}

The present study was approved by the Ethics Committee of Bengbu Medical College (Bengbu, China).

\section{Patient consent for publication}

Not applicable.

\section{Competing interests}

The authors declare that there is no conflict of interest.

\section{References}

1. Flannagan RS, Jaumouillé V and Grinstein S: The cell biology of phagocytosis. Annu Rev Pathol 7: 61-98, 2012.

2. Rosales C and Uribe-Querol E: Phagocytosis: A fundamental process in immunity. Biomed Res Int 2017: 9042851, 2017.

3. Gordon S: Phagocytosis: An immunobiologic process. Immunity 44: 463-475, 2016.

4. Shklover J, Levy-Adam F and Kurant E: Apoptotic cell clearance in development. Curr Top Dev Biol 114: 297-334, 2015.

5. Alva-Murillo N, López-Meza JE and Ochoa-Zarzosa A: Nonprofessional phagocytic cell receptors involved in Staphylococcus aureus internalization. Biomed Res Int 2014: 538546, 2014.

6. Juncadella IJ, Kadl A, Sharma AK, Hochreiter-Hufford A, Borish L and Ravichandran KS: Apoptotic cell clearance by bronchial epithelial cells critically influences airway inflammation. Nature 493: 547-551, 2013.

7. Yakar S and Adamo ML: Insulin-like growth factor 1 physiology: Lessons from mouse models. Endocrinol Metab Clin North Am 41: 231-247, 2012.

8. Troncoso R, Ibarra C, Vicencio JM, Jaimovich E and Lavandero S: New insights into IGF-1 signaling in the heart. Trends Endocrinol Metab 25: 128-137, 2014.

9. Wang Z, Li W, Guo Q, Wang Y, Ma L and Zhang X: Insulin-like growth factor-1 signaling in lung development and inflammatory lung diseases. Biomed Res Int 2018: 6057589, 2018.

10. Narasaraju TA, Chen H, Weng T, Bhaskaran M, Jin N, Chen J, Chen Z, Chinoy MR and Liu L: Expression profile of IGF system during lung injury and recovery in rats exposed to hyperoxia: a possible role of IGF-1 in alveolar epithelial cell proliferation and differentiation. J Cell Biochem 97: 984-998, 2006.

11. Dos Santos Reis MD, Dos Santos YMO, de Menezes CA, Borbely KSC and Smaniotto S: Resident murine macrophage migration and phagocytosis are modulated by growth hormone. Cell Biol Int 42: 615-623, 2018.

12. Yao X, Wang W, Li Y, Huang P, Zhang Q, Wang J, Wang W, Lv Z, An Y, Qin J, et al: IL-25 induces airways angiogenesis and expression of multiple angiogenic factors in a murine asthma model. Respir Res 16: 39, 2015.

13. BahramiMahneh S, Movahedi M, Aryan Z, Bahar MA, Rezaei A, Sadr M and Rezaei N; Universal Scientific Education and Research Network (USERN): Serum IL-33 is elevated in children with asthma and is associated with disease severity. Int Arch Allergy Immunol 168: 193-196, 2015.

14. Jung HJ and Suh Y: Regulation of IGF-1 signaling by microRNAs. Front Genet 5: 472, 2015.

15. Hoshino M, Nakamura Y, Sim JJ, Yamashiro Y, Uchida K, Hosaka $\mathrm{K}$ and Isogai S: Inhaled corticosteroid reduced lamina reticularis of the basement membrane by modulation of insulin-like growth factor (IGF)-I expression in bronchial asthma. Clin Exp Allergy 28: 568-577, 1998.

16. Préfontaine D, Nadigel J, Chouiali F, Audusseau S, Semlali A, Chakir J, Martin JG and Hamid Q: Increased IL-33 expression by epithelial cells in bronchial asthma. J Allergy Clin Immunol 125: 752-754, 2010.

17. Préfontaine D, Lajoie-Kadoch S, Foley S, Audusseau S, Olivenstein R, Halayko AJ, Lemière C, Martin JG and Hamid Q: Increased expression of IL-33 in severe asthma: Evidence of expression by airway smoothmuscle cells. J Immunol 183: 5094-5103, 2009.

18. Kurowska-Stolarska M, Stolarski B, Kewin P Murphy G, Corrigan CJ, Ying S, Pitman N, Mirchandani A, Rana B, van Rooijen N, et al: IL-33 amplifies the polarization of alternatively activated macrophages that contribute to airway inflammation. J Immunol 183: 6469-6477, 2009.

19. Lloyd CM: IL-33 family members and asthma-bridging innate and adaptive immune responses. Curr Opin Immunol 22: 800-806, 2010

20. Nile CJ, Barksby E, Jitprasertwong P, Preshaw PM and Taylor JJ: Expression and regulation of interleukin-33 in human monocytes. Immunology 130: 172-180, 2010.

21. Ahluwalia A, Jones MK, Hoa N and Tarnawski AS: NGF protects endothelial cells from indomethacin-induced injury through activation of mitochondria and upregulation of IGF-1. Cell Signal 40: 22-29, 2017. 
22. Szczęsny E, Slusarczyk J, Głombik K, Budziszewska B, Kubera M, Lasoń W and Basta-Kaim A: Possible contribution of IGF-1 to depressive disorder. Pharmacol Rep 65: 1622-1631, 2013.

23. Wang Y, Bai Y, Li Y, Liang G, Jiang Y, Liu Z, Liu M, Hao J, Zhang $\mathrm{X}, \mathrm{Hu} \mathrm{X}$, et al: IL-15 enhances activation and IGF-1 production of dendritic epidermal $\mathrm{T}$ cells to promote wound healing in diabetic mice. Front Immunol 8: 1557, 2017.

24. Fritz JM, Dwyer-Nield L and Malkinson AM: Stimulation of neoplastic mouse lung cell proliferation by alveolar macrophage-derived, insulin-like growth factor- 1 can be blocked by inhibiting MEK and PI3K activation. Mol Cancer 10: 76, 2011.

25. Knuever J, Willenborg S, Ding X Akyüz MD, Partridge L, Niessen CM, Brüning JC and Eming SA: Myeloid cell-restricted Insulin/IGF-1 receptor deficiency protects against skin inflammation. J Immunol 195: 5296-5308, 2015.

26. Piñeiro-Hermida S, Gregory JA, López IP, Torrens R, Ruíz-Martínez C, Adner M and Pichel JG: Attenuated airway hyperresponsiveness and mucus secretion in HDM-exposed Igf1r-deficientmice. Allergy 72: 1317-1326, 2017.
27. Vieira RP, Silva RA, Oliveira-Junior MC, Greiffo FR, Ligeiro-Oliveira AP, Martins MA and Carvalho CR: Exercise deactivates leukocytes in asthma. Int J Sports Med 35: 629-635, 2014.

28. Vieira RP, de Andrade VF, Duarte AC, Dos Santos AB, Mauad T, Martins MA, Dolhnikoff M and Carvalho CR: Aerobic conditioning and allergic pulmonary inflammation in mice. II. Effects on lung vascular and parenchymal inflammation and remodeling. Am J Physiol Lung Cell Mol Physiol 295: L670-L679, 2008.

29. Vieira RP, Duarte AC, Claudino RC, Perini A, Santos AB, Moriya HT, Arantes-Costa FM, Martins MA, Carvalho CR and Dolhnikoff M: Creatine supplementation exacerbates allergic lung inflammation and airway remodeling in mice. Am J Respir Cell Mol Biol 37: 660-667, 2007.

30. Ferreira SC, Toledo AC, Hage M, Santos AB, Medeiros MC, Martins MA, Carvalho CR, Dolhnikoff $M$ and Vieira RP: Creatine activates airway epithelium in asthma. Int J Sports Med 31: 906-912, 2010.

31. Xiao W, Chen P, Wang R and Dong J: Overload training inhibits phagocytosis and ROS generation of peritoneal macrophages: Role of IGF-1 and MGF. Eur J Appl Physiol 113: 117-125, 2013. 